\title{
Foreign Direct Investment and Host-Country Trading Blocs
}

\author{
Jeff Heinrich \\ University of Wisconsin-Whitewater
}

Denise Eby Konan
University of Hawaii

\begin{abstract}
We consider the impact of preferential trade agreements (PTAs) on horizontal foreign direct investment (FDI) coming from parent countries outside the PTA. While easier access to a larger market due to a PTA may justify new FDI, preexisting investments may be rationalized as firms concentrate production in a single plant in the PTA. Which effect dominates depends on the extent of pre-PTA tariff jumping. The number of firms in the industry and non-PTA welfare may rise or fall. PTA welfare increases regardless of PTA-induced changes in inward FDI.

- JEL Codes: F12, F15, F23

- Key Words: Multinational Enterprise, Foreign Direct Investment, Regional Integration, Preferential Trade Agreements
\end{abstract}

\section{Introduction}

The plodding progress on global, multilateral trade liberalization is accompanied by renewed interest in discriminatory trade liberalization in the form

\footnotetext{
*Corresponding Address: Dr. Heinrich, Assistant Professor, Department of Economics, University of Wisconsin-Whitewater, Whitewater, WI 53190, USA, Phone: +262.472 .5583 , Fax: +262.472 .4863 , Email: heinricj@uwwvax.uww.edu. Dr. Konan, Associate Professor, Depart-ment of Economics, University of Hawaii, Honolulu, HI 96822 USA, Phone: +808.956.6310, Fax:: +808.956.4347, Email: konan@hawaii.edu.
} 
of preferential trade agreements (PTAs). Many developing countries now seem eager to participate in such extra-national cooperatives. Examples are numerous: Mexico's ascension to the Canada-US Free Trade Agreement (CUSFTA) to form NAFTA, and the desire of other American nations to do the same; Mediterranean and Central European countries negotiating bilateral PTAs with the European Union; the MERCOSUR customs union encompassing Brazil, Argentina, Paraguay, and Uruguay, with several other South American nations showing interest in joining; and the deepening interaction in the Association of South-East Asian Nations (ASEAN). The motivation of individual nations varies, but in many cases the expanded market access due to the PTA is hoped to lure increased foreign direct investment (FDI) into the country. However, it is not clear to what extent PTA formation will increase FDI inflows, if at all. While the trade literature abounds with analyses of PTAs, studies which consider the impact of PTA formation on FDI are much fewer. This paper seeks to shed some light on this issue.

That PTAs impact FDI flows finds some empirical support. The early stages of European integration, a period notable mostly for reduced tariffs on intraEuropean trade, saw a significant increase in US FDI into the European Common Market due to EC formation. ${ }^{1}$ More recently, Aristotelous and Fountas (1996) find that the introduction of a single European market in 1993 under the Single Market Program led to increased U.S. and Japanese FDI there, and argue persuasively that this is due to a perception of a larger, more integrated European market. Using survey data, Bannister, Primo Braga and Petry (1994) find that the formation of MERCOSUR positively influenced investment into the region. Blomström and Kokko (1996) examine the impact of several regional integration agreements (CUSFTA, NAFTA, MERCOSUR) and find scope for positive influences, but note that FDI may respond to policy shifts in a temporally asynchronous fashion. Using a more rigorous methodology, Globerman and Shapiro (1999) find that Canadian FDI, inward and outward, increased significantly with the advent of CUSFTA and NAFTA. Most of these studies are quick to point out that regional integration is in practice often accompanied by broader economic reforms that may have a more significant impact on FDI flows.

Lay thinking on PTAs often holds that if free trade is desirable, then PTA formation which reduces some trade barriers is also desirable. Viner (1950) was

${ }^{1}$ UNCTC (1993) summarizes several studies on the impact of European integration on FDI. 
the first to dispel this notion by suggesting that countries may lose when they switch to more expensive suppliers due to tariff preferences, the 'trade diversion' phenomenon. ${ }^{2}$ Bhagwati and Panagariya (1996) suggest that small countries, such as most developing countries, joining in PTAs may be particularly susceptible to losses, as they are more likely to have higher trade barriers that translate into predominantly unilateral reforms vis-à-vis their larger, more liberal PTA partners. Modern theory that incorporates a role for the industrial organization of firms is often more optimistic in its conclusions. In their excellent survey, Baldwin and Venables (1995) note that regional integration can deliver significant gains in the form of scale economies and pro-competitive effects in models with imperfect competition and increasing returns to scale. The larger market and increased competition brought on by integration increases the perceived elasticity of demand and lowers markups, benefiting consumers. Larger production runs lower average costs, and the exit of redundant firms frees resources for competing uses.

However, none of these analyses allows for multinational production. PTAs are at best second-best, as they simply alter the pattern of trade distortion by preferentially lowering the cost of trade with partners. Multinational firms often arise as a reaction to trade distortions, so there is strong reason to believe they would respond to shifts in the pattern of distortion. Multinationals typically own large stocks of intangible assets which are non-rival with respect to other inputs and can be brought to bear in any location at low cost (Caves (1996) and Markusen (1995)). If such firm-specific costs (in generating the asset) are a large proportion of total costs, the firm might jump the trade barrier (such as a tariff wall) by supplanting exports with a new facility that produces locally. ${ }^{3}$ Horstmann and Markusen (1992) and Markusen and Venables (1998) point out that overlooking multinationality can lead to erroneous conclusions about the effects of trade policy by failing to account for shifting production patterns. In the context of PTAs, Ethier (1998) shows that small countries have potential to gain from marginal tariff preferences with larger nations when said preferences redirect FDI inward from competing non-member host countries. This is contrary to traditional analysis, which finds a bias towards losses for such countries.

One of the very few studies to look explicitly at regional integration and FDI,

\footnotetext{
${ }^{2}$ Lipsey (1960) surveys the early literature, treating welfare and trade pattern effects.

3'Tariff jumping' can take several forms, including licensing assets to or engaging in a joint venture with local firms, or establishing a wholly-owned subsidiary through greenfield investment or acquisition of a local firm. FDI typically implies the subsidiary approach.
} 
Motta and Norman (1996) extend the approach of Horstmann and Markusen (1992) by modeling two countries integrating in a three-country world, each with an indigenous oligopolist operating under Cournot conjectures facing a tradeoff between the fixed cost of a production subsidiary and trade costs incurred when exporting. They identify a rationalization effect as regional firms rationalize their FDI and switch to intra-regional exporting, with this FDI to some extent being replaced by the external firm, which establishes an export platform in the region that also contributes to additional intra-regional trade. ${ }^{4}$

This paper adopts the industrial organization approach to modeling FDI to gain additional insight into how production location decisions respond to PTA formation. ${ }^{5}$ The papers by Ethier (1998) and Motta and Norman (1996) focus on attracting FDI from other PTA member countries. We consider a different issue the ability of regional agreements like MERCOSUR and ASEAN to attract horizontal FDI from non-member countries. We extend the basic framework of Markusen and Venables (1998) which features monopolistically competitive firms and increasing returns to scale at both the firm and plant levels. ${ }^{6}$ Thus, our analysis differs from that of Motta and Norman in which there is no role for firm-level scale economies (the number of firms is fixed) and welfare effects in the nonmember countries are not considered. We arrive at two main findings. First, the degree to which integration spurs additional FDI depends on the level of the initial trade distortion. At lower levels of distortion, a 'market expansion' effect will bring in FDI where there was none before as the larger integrated market justifies incurring additional plant costs. However, at higher levels of distortion existing FDI is rationalized as MNEs reduce the number of regional plants, the rationalization effect mentioned previously. Second, the market expansion effect is associated with a decrease in the total number of firms in the world, an increase in host-country welfare and a reduction in rest-of-the-world welfare, while the rationalization effect is associated with an increase in the total number of firms and an increase in the welfare of all countries. Third, price equilibria are sensitive to both the size of plant-specific and firm-specific fixed costs relative to market size in both the integrating countries and the rest of the world, and prices in the

\footnotetext{
${ }^{4}$ Robson and Wooton (1993) also examine integration and FDI, considering the efficiency consequences when parents and subsidiaries are located within the integrating countries with no outside firms.

${ }_{5}^{5}$ In addition to papers already mentioned, related models of FDI include Markusen (1984), Helpman (1985), and Horstmann and Markusen (1987). Nearly all such models consider only two countries.

${ }^{6}$ In a companion paper (Konan and Heinrich, 2000), we use computational methods to analyze the model with asymmetric countries and general equilibrium effects.
} 
integrating region are sensitive to the relative sizes of the integrating region and the rest of the world. We find firm-level economies of scale to be important in determining price equilibria.

\section{The General Model}

We assume there to be three countries, two of which, denoted $A$ and $B$, can join in a preferential trade agreement (PTA), while the rest of the world, denoted $R$ or $R O W$, is exogenously excluded from participation in the agreement. $A$ and $B$ are held to be identical in all respects. Our partial equilibrium analysis focuses on a single industry producing a single good, $X . X$ is produced with increasing returns in a monopolistically competitive environment with free entry and exit. $X$ production requires a firm-specific fixed cost $F$ incurred in the country of ownership, as well as a plant-specific fixed cost $G$ that must be incurred in every country in which the firm maintains a production facility. All fixed costs are assumed to be constant across all countries. Marginal production costs in country $i$, denoted $c_{i}$, are assumed to be constant and equal across countries $\left(c_{i}=c \forall i\right)$ and production scales.

$X$ producers may be national or multinational, with the existence of subsidiaries being the distinguishing feature. We assume the integrating countries cannot supply the firm-specific asset critical to $X$ production, thus eliminating the possibility of any $X$ firms being based there. Thus, all national firms will be located in $R O W$, and such firms will be denoted in general as type- $n$. Multinational firms are then also exclusively headquartered in $R O W$ and maintain a single plant there. Multinationals can maintain a single plant in either of the integrating countries, such denoted type- $m i$ for $i=A, B$, in number $m_{A}$ and $m_{B}$ corresponding to the location of the subsidiary manufacturing facility, ${ }^{7}$ or maintain a plant in all countries, denoted type- $m A B$ in number $m_{A B}$. We assume multinationals service either $A$ or $B$ from plants within the integrating region, and further assume that investment into the integrating region is evenly distributed between $A$ and $B$ $\left(m_{A}=m_{B}\right)$. Exports face a transport cost $\tau$ which must be incurred by the exporter (such as sales in $B$ of type $n$ or $m A$ firms) and are specified as a cost per unit of $X$ exported. Trade costs are assumed to be initially identical between all countries, i.e., that $\tau_{i j}=\tau, i, j=(A, B, R), i \neq j$, where $\tau_{i j}$ is the specific transport cost per unit of $X$

\footnotetext{
${ }^{7} m i$ will denote firms with a single subsidiary in the integrating region before PTA formation. After integration, such firms will be denoted $m u$.
} 
shipped from $i$ to $j$. We specify $\tau$ to be a positive ratio of marginal costs, $\tau=t c, t>0$.

We assume demand for $X$ in every country, ala Cobb-Douglas preferences, to be

$$
X_{i c}=E_{i} / p_{i}
$$

where $E_{i}$ is expenditure on $X$ in country $i, p_{i}$ is its price there and $X_{i c}$ is the sum of sales of $X$ in country $i$;

$$
\begin{aligned}
& X_{R c}=X_{R R}^{n}+X_{R R}^{m A}+X_{R R}^{m B}+X_{R R}^{m A B} \\
& X_{A c}=X_{R A}^{n}+X_{A A}^{m A}+X_{B A}^{m B}+X_{A A}^{m A B} \\
& X_{B c}=X_{R B}^{n}+X_{A B}^{m A}+X_{B B}^{m B}+X_{B B}^{m A B},
\end{aligned}
$$

where $X_{i j}^{k}$ is the sales in country $j$ of an individual type- $k$ firm producing in country $i$. Expenditure on $X$ is fixed in each country, and $A$ and $B$ spending on $X$ is a constant portion $y$ of that in $R O W, 0<y \leq 1$. Calling $E_{R} \equiv E$, then $E_{A}=E_{B}=y E$.

Pricing in the $X$ market will be determined by the condition that marginal revenue equals marginal cost. Given demand, this will entail price set as a markup over marginal cost. Denote the markup $e_{i j}^{k}$ in country $j$ as that of a type- $k$ firm producing in country $i$. Cournot conduct is assumed by firms in the $X$ sector, implying marginal cost markups equal market share divided by own-price elasticity of demand. Recognizing that constant-expenditure demand functions require own-price elasticities of unity, the markup is simply equal to each firms market share,

$$
e_{i j}^{k}=\frac{X_{i j}^{k}}{X_{i c}}=\frac{p_{j} X_{i j}^{k}}{E_{j}}
$$

Given the extensive symmetry assumptions, the price of $X$ in $A$ and $B$ will be equal. This will be the case both before and after PTA formation, though integration will result in a change in the price of $X$ in all countries. Hereafter, the price of $X$ in the integrating countries will be denoted $p_{u}\left(=p_{A}=p_{B}\right)$. This then implies markups for a given firm type will also be equivalent in $A$ and $B$, $e_{i A}^{k}=e_{i B}^{k}=e_{i u}^{k}$. The $u$ subscript denotes a single integrating country, rather than the whole union.

Before integration, there is an ambiguity as to production regime which appears in analyzing the model. We will assume a zero profit condition, and firms under such a condition are essentially trading off fixed subsidiary costs against trade costs, and these effects are additive across the two integrating markets. Firms are 
indifferent between choosing to invest in one country or both if they invest in either, and we address this ambiguity by assuming that if a firm invests in either $A$ or $B$, then it will invest in both. Thus, single-subsidiary multinationals (type- $m i$ ) will not exist before integration. ${ }^{8}$

Firms choose outputs such that marginal revenue equals marginal cost, with firms choosing no output if MC exceeds MR. Marginal cost is $c$ for firms not subject to trade costs, and $c(1+t)$ for firms that are. As marginal revenue is price times 1 minus the markup, the pricing equations for all firms in the $R O W$ market and multinationals in $A$ and $B$ are then (assuming positive outputs)

$$
p_{R}\left(1-e_{R R}^{k}\right)=p_{u}\left(1-e_{u u}^{m A B}\right)=c, k=n, m A B
$$

while the pricing equation for national firm sales in $A$ and $B$ is

$$
p_{u}\left(1-e_{R u}^{n}\right)=c(1+t)
$$

Putting (2) together with (3) and (4), we can obtain relations for outputs in terms of prices,

$$
\begin{gathered}
X_{R R}^{k}=E \frac{p_{R}-c}{p_{R}^{2}}, k=n, m A B, \\
X_{R u}^{n}=y E \frac{p_{u}-(c+t)}{p_{R}^{2}} \\
X_{u u}^{m A B}=y E \frac{p_{u}-c}{p_{u}^{2}}
\end{gathered}
$$

Firms in the $X$ industry are monopolistically competitive, so free entry and exit will drive profits to zero. The zero profit condition is equivalent to the requirement that markup revenues be equal to fixed costs. For national firms, this condition is expressed as

$$
p_{R} e_{R R}^{n} X_{R R}^{n}+2 p_{u} e_{R u}^{n} X_{R u}^{n}=G+F
$$

and the condition for pre-integration multinationals is

$$
p_{R} e_{R R}^{m A B} X_{R R}^{m A B}+2 p_{u} e_{u u}^{m A B} X_{u u}^{m A B}=3 G+F
$$

Substituting for $X$ from (5)-(7) and the markup from (2) and considering the case when all outputs are positive, conditions (8) and (9) become

\footnotetext{
${ }^{8}$ Formal analysis leading to this assumption is contained in an appendix, which also discusses how the results might be altered were this assumption relaxed.
} 


$$
\begin{aligned}
& E\left(\frac{p_{R}-c}{p_{R}}\right)^{2}+2 y E\left(\frac{p_{u}-c(1+t)}{p_{u}}\right)^{2}=G+F, \\
& E\left(\frac{p_{R}-c}{p_{R}}\right)^{2}+2 y E\left(\frac{p_{u}-c}{p_{u}}\right)^{2}=3 G+F
\end{aligned}
$$

The pre-integration $X$ sector is thus defined with the number of each firm type given in (10) and (11), outputs given by in (5)-(7), and goods prices given in (3) and (4).

\section{PTA Formation}

Suppose that countries $A$ and $B$ enter into a regional integration agreement such that the cost of trade between them is eliminated and consumers are able to arbitrage across the two regions. ${ }^{9}$ Trade in goods within the PTA is integrated $\left(t_{A B}=t_{B A}=0\right)$, but with fixed and variable costs left unaffected. Multinationals can now service both $A$ and $B$ from a single plant in either without incurring trade costs. Under this condition, no firm would ever want to maintain two plants in the integrating region and type- $m A B$ firms will not exist $\left(m_{A B}=0\right)$. Rather, such firms will reduce the number of plants they maintain in the PTA. Strictly national firms based in $R$ will see no change in the world environment (aside from the number and composition of competitors) as the assumption of uniform trade costs eliminates any incentive for supplying a high trade cost PTA partner with exports deflected through the low trade cost partner. In addition, upon integration the $A$ and $B$ markets are considered unified with no price discrimination possible and we let $p_{u I}$ be the integrated, post-union price in $A$ and $B$. As the model specification is largely unaffected, we simply note the following change to (11), the zero-profit condition for post-integration multinationals (denoted type-mu),

$$
E\left(\frac{p_{R}-c}{p_{R}}\right)^{2}+2 y E\left(\frac{p_{u l}-c}{p_{u l}}\right)^{2}=2 G+F .
$$

\section{Solving the Model}

The systems of zero-profit conditions (11) and (12) and their post-integration counterparts are highly non-linear in prices so closed-form solutions are not

${ }^{9}$ Due to the assumptions employed, this integration agreement is in effect a customs union if we interpret the trade cost as a tariff. 
viable, but we can still obtain some analytical results. Defining $g \equiv G / E$ and $f \equiv F / E$, rearranging terms allows us to rewrite the pre-PTA zero profit condition (10) for national firms as

$$
\frac{\left(\left(p_{R}-c\right) / p_{R}\right)^{2}}{g+f}+\frac{\left(\left(p_{u}-c(1+t)\right) / p_{u}\right)^{2}}{(g+f) / 2 y}=1
$$

(13) describes the zero profit locus for national firms which we denote $\pi_{n}$. This equation describes an ellipse in markup space, with center at $e_{R i}=0$, a horizontal diameter along the $e_{R u}$ axis of $2[(\mathrm{~g}+f) / 2 y]^{1 / 2}$ and a vertical diameter along the $e_{R R}$ axis of $2(g+f)^{1 / 2}$. This locus can be represented on the $\left(p_{u}, p_{R}\right)$ price plane in a slightly distorted form, with the horizontal and vertical diameters proportional to those above and the center at $(c(1+t), c) .{ }^{10}$ Price pairs located within the ellipsoid are associated with negative profits.

Replicating the procedure characterizes the zero profit locus for pre-PTA multinationals, dubbed $\pi_{m A B}$, and that for post-union multinationals, dubbed $\pi_{m u}$. The latter is of the form

$$
\frac{\left(\left(p_{R}-c\right) / p_{R}\right)^{2}}{2 g+f}+\frac{\left(\left(p_{u l}-c\right) / p_{u l}\right)^{2}}{(3 g+f) / 2 y}=1 .
$$

which is centered at $(c, c)$. The former becomes

Figure 1. Determining Price Equilibrium

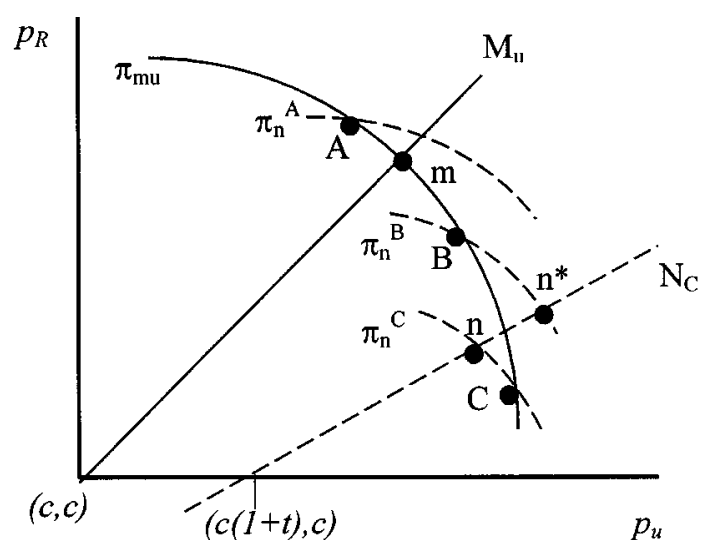

Note: Given supply conditions and zero-profit loci. Axes shown intersect at $(c, c)$, and not the price origin. $N_{A}$ and $N_{B}$ not shown.

\footnotetext{
${ }^{10}$ The center coordinates are determined by setting the numerators for each term on the left hand side of (13) equal to zero and solving for the respective coordinate. Throughout the paper, we follow the convention of $R O W$ prices being on the vertical axis and PTA prices being on the horizontal axis.
} 


$$
\frac{\left(\left(p_{R}-c\right) / p_{R}\right)^{2}}{3 g+f}+\frac{\left(\left(p_{u}-c\right) / p_{u}\right)^{2}}{(2 g+f) / 2 y}=1,
$$

also centered at $(c, c)$. Thus, $\pi_{m A B}$ lies outside of $\pi_{m u}$. We shall concern ourselves with the region of the ellipsoid consistent with non-negative markups, i.e., north-east of center.

Price equilibrium will entail either a single firm type (homogeneous regime) or many (mixed regime). Characterization of equilibrium prices requires the inclusion of demand and supply conditions. For the purposes of describing equilibrium, suppose a post-PTA situation. In an equilibrium with only national firms, demand and supply market-clearing conditions require that

$$
n X_{R R}^{n}=E / p_{R}, n X_{R u}^{n}=y E / p_{u}
$$

which, when combined with the supply equations (5) and (6), yield the expression

$$
p_{R} / p_{u}=(1+t)^{-1} \text {. }
$$

Equation (17) holds for the sets of prices at which only national firms exist. This corresponds to the "national firm ray," labeled $N_{C}$ in Figure 1, from the origin through the center of $\pi_{n}{ }^{11} \mathrm{~A}$ similar procedure presupposing only post-PTA multinationals gives us a characterization of the multinational ray $\left(M_{u}\right)$,

$$
p_{R} / p_{u}=1
$$

Thus, $N$ always lies below $M_{u}$ for $t>0$. If both firm types are active, then equilibrium prices lie between $N$ and $M_{u}$ and approach one or the other as the relative number of firms of that type increases.

Price equilibrium is determined by the intersection of the zero-profit loci contingent on this intersection being between $N$ and $M_{u} \cdot{ }^{12}$ Figure 1 shows three potential intersections of the zero-profit loci, points (A), (B) and (C), where $t_{A}>t_{B}>t_{C}$. At point (A) both nationals and multinationals would earn zero profits, but that equilibrium entails a negative number of national firms and so is not feasible. Rather, equilibrium will be at point $(\mathrm{m})$ where $M_{u}$ intersects the zeroprofit locus of multinationals and there will be only multinationals in equilibrium

\footnotetext{
${ }^{11}$ In the figures, the center of the coordinate system is at $(c, c)$, not the origin. Thus, $\mathrm{N}$ does not go through the illustrated intersection of the horizontal and vertical axes for any positive trade cost.

${ }^{12}$ Proof and supporting discussion can be found in Markusen and Venables (1998). Briefly, no nonnegative combination of number of firms of both types can offer supplies consistent with prices outside the cone bounded by $N$ and $M_{u}$.
} 
Figure 2. Pre- and Post-integration Price Equilibria ( $\alpha$ and $\beta$, respectively) for Various Trade Costs.

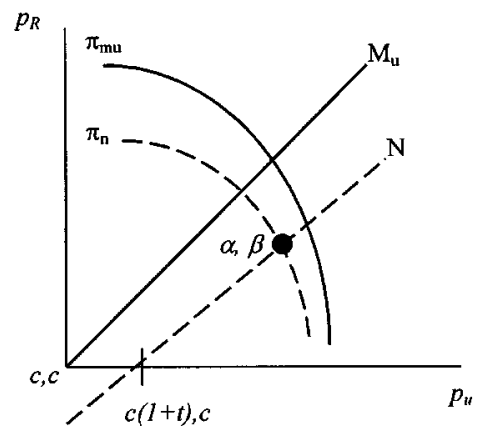

Panel 1

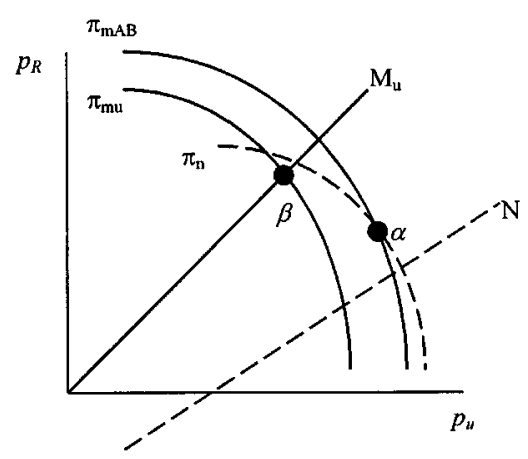

Panel 3

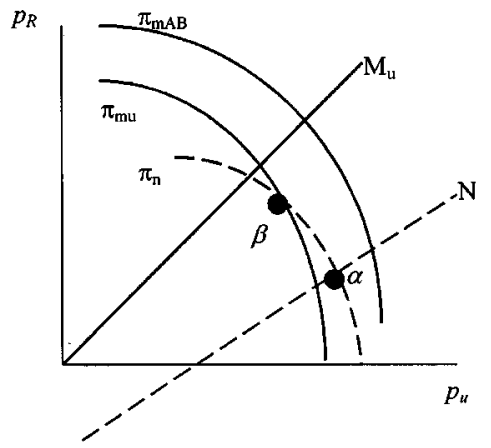

Panel 2

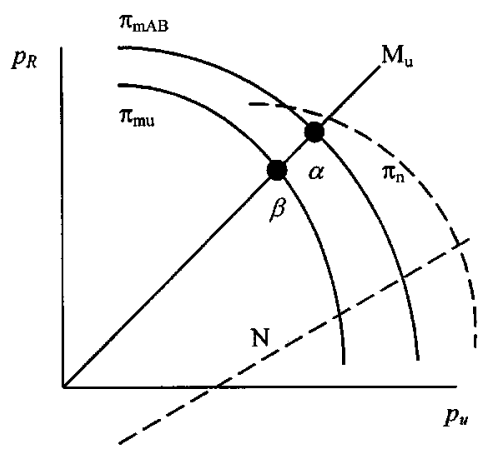

Panel 4

Note: As we move from panel to panel, the trade cost is increasing in value.

(national firms are earning negative profits at $(\mathrm{m})) .{ }^{13}$ At an intersection of the zero-profit loci that lies between $N$ and $M_{u}$, such as (B), both firm types exist in equilibrium and prices are determined at that point. At intersections below $N$, such as (C), multinationals cannot be supported, and equilibrium will be at point (n) consistent with only national firms. A similar procedure will determine the preintegrated equilibrium, with the price ratio consistent with only $m A B$ firms also being that given by (18).

We can obtain solutions for some prices. Several comparative static exercises are of interest, and many for a two-county world are treated in Markusen and

\footnotetext{
${ }^{13}$ This can only happen if $\pi_{n}$ is high enough such that its highest point on the vertical axis is above (m), which is the case provided $f / g>(1-2 y) / 2 y$, i.e., that the plant-specific cost is not 'too large' relative to firm-specific cost, with too large being relative to the size of the integrating markets. We will henceforth assume $f / g>(1-y) / y$, which is a similar (stronger) condition on the intersection of $\pi_{n}$ and $\pi_{m A B}$.
} 
Venables (1998). We proceed to examine the subject of interest, the integration of $A$ and $B$.

\section{A. PTA Formation and Initial Trade Costs}

We are now able to address the changes in production regime brought on by integration, which drives the transport cost between $A$ and $B$ to zero. First consider the influence of trade costs, starting from the degenerate case of frictionless, free trade with all trade costs set to zero. All zero profit loci will have similar shape and centers, with diameters varying according to the value of $f, g$, and $y . \pi_{n}$, with the lowest fixed cost, is innermost; $\pi_{m u}$ outside of $\pi_{n}$, and $\pi_{m A B}$ outside of that. No multinationals will exist before or after integration and all demand for $\mathrm{X}$ in $A$ and $B$ will be met by imports from $R O W$, as in Panel 1 of Figure 2. Now let trade costs increase. The center of $\pi_{n}$ shifts right and the $N$ ray will rotate clockwise about the origin, becoming flatter. As trade costs increase from zero, $\pi_{n}$ will eventually intersect $\pi_{m u}$. There will be no change in the production regime until this intersection occurs above $N$; call the value of $t$ at which this occurs $t_{1} \cdot{ }^{14}$ For all $t>t_{1}$ and only those values, multinationals will exist after PTA formation. For $t$ just above $t_{1}$, however, only national firms exist before integration. In these cases (Panel 2) there is clear investment creation, as the expanded market resulting from integration justifies the fixed cost of subsidiaries, a "market expansion" effect.

Higher trade costs lead to relatively fewer national firms after integration, such being displaced completely at trade $\operatorname{cost} t_{2}$ where $\pi_{n}$ intersects $\pi_{m u}$ on $M_{u}$. As trade costs continue to grow, $\pi_{n}$ will come to intersect $\pi_{m A B}$ as well, but analogous to before there will not be any multinationals in the pre-integration situation until this intersection occurs above $N$ (Panel 3); call the corresponding trade cost $t_{3}$. At this level of trade costs, no national firms exist after integration. ${ }^{15}$ As initial trade costs continue to increase the proportion of pre-integration multinationals, relative to national firms, continues to increase until the intersection of $\pi_{n}$ and $\pi_{m A B}$ lies on $M_{u}$ at $t=t_{4}$. For $t \geq t_{4}$ integration results in the reduction of plants MNEs maintain in the PTA as firms rationalize production into a single plant located in the PTA, a "rationalization" effect. We summarize with a proposition.

Proposition 1: For $t<t_{1}$, integration has no effect on production regime and no multinationals exist. For $t_{1}<t<t_{2}$, no multinationals exist before integration, but integration will prompt FDI into the

\footnotetext{
${ }^{14}$ The various critical values of $t$ for regime shifting are algebraically unwieldy, and so are relegated with supporting discussion to the technical notes available from the authors.

${ }^{15}$ This result is contained in the technical notes.
} 
integrating region. For $t_{2}<t<t_{3}$, no MNEs exist before integration but completely dominate production after integration. For $t_{3}<t<t_{4}$, there will be some FDI before integration and postintegration production is dominated by MNEs. For $t>t_{4}$, MNEs dominate production both before and after integration.

Thus, the extent to which integration spurs investment into the region will depend largely on how bad the initial trade distortion was. Economies with heavily distorted trade regimes are more likely to see reduced investment as firms rationalize region-wide production (rationalization effect) while mildly distorted trade regimes are more likely to see increased investment as the larger market ensuing from integration justifies the cost of an additional plant (market size effect).

\section{B. Fixed Costs and Country Size}

The diameters of the zero profit loci depend directly on the ratio of fixed costs to expenditure in the $X$ sector, with expenditure in turn directly related to income. An increase in the diameters makes FDI less likely at any given level of trade distortion, or alternatively a higher distortion is required to motivate any given amount of FDI (in terms of the ratio of MNEs to national firms). Thus a symmetric decrease in income holding fixed costs constant will imply a lesser likelihood of FDI at any given initial distortion. Also, as is now well appreciated in the FDI literature, the predominance of plant-level scale economies over firm-level scale economies makes it less desirable for a firm to establish multiple plants and tends to favor the existence of national firms over MNEs. Here, this would reflect a decrease in the $f / g$ ratio which would increase the diameters of the MNEs zero profit loci proportionately more than the locus for national firms, again dictating a lower FDI response at any given distortion level. Additionally, the effects due to different trade costs discussed above would occur over a wider range of $t$.

One of the few asymmetries this partial equilibrium analysis can handle is income differences between the integrating region and $R O W$. Consider an income shift from the integrating region to $R O W$ holding world income constant. If all firms are of any one single type, then firms are indifferent to the distribution of income and profitability is unaffected. Thus, all zero profit loci will intersect the corresponding mono-firm ray at a constant point regardless of the distribution of income (holding world income constant). This change in the distribution of income decreases the vertical diameters of all loci and simultaneously increases the horizontal diameters, rotating the loci counterclockwise about their intersections with the corresponding mono-firm ray (i.e., about (m) for $\pi_{m u}$ ). 
Consider Figure 1 again, supposing (B) as the initial point. As income is transferred from the PTA to $R O W$, the $\pi_{m u}$ locus moves out while the $\pi_{n}$ locus moves in. The equilibrium point will move closer to $N$, lowering the equilibrium $p_{R}$ and raising $p_{u}$, and making national firms a larger portion of the industry. If we suppose a $t$ such that only MNEs are active before and after integration, successively larger increases in the income transfer will first introduce national firms into the pre-integration equilibrium. Then MNEs will be squeezed out of the pre-integration equilibrium and national firms will exist after integration. Thus, the smaller the integrating region is relative to the rest of the world, the less likely is FDI for any given trade cost, as the potential for over-investment into the fragmented region is less. Smaller integrating countries are more likely to see additional investment (if any) as integration will be more likely to see a market expansion effect that brings FDI into the PTA than a rationalization effect that reduces existing FDI. A reduction in $y$ would yield qualitatively identical effects. This contrasts with Motta and Norman (1996) who find that country size has less effect on prices and more impact on the dispersion of FDI in the integrating region.

\section{Number of Firms}

Integration has consequences for the number of firms in equilibrium. By assumption each firm, regardless of type, maintains a plant in $R O W$ and $R O W$ is constrained to have no $X$ imports. Thus the output and markup of every firm in ROW is identical. With constant marginal costs and incomes, an increase in $p_{R}$ increases the markup $e_{R R}$ which implies via (2) that market share must increase for each firm. An increase in market share can only occur if some firms are forced to exit. The total number of firms is thus strictly decreasing in $p_{R}$, ceteris paribus.

For all $t, t_{1}<t<t_{3}$, integration entails an increase in $p_{R}$, as at least some MNEs will exist after integration. For these distortion levels, the market size effect will bring foreign investment into the PTA but will also entail a decrease in the total number of firms. Firms individually are diversifying production across several plants, but the industry as a whole is rationalizing production into fewer firms. When external trade costs are high enough, distortion-jumping FDI increases competition in the PTA which culls some (or all) national firms, which lessens competition in $R O W$ as MNEs are better able to use revenues raised in the PTA to support firm-specific costs.

For $t>t_{4}, p_{R}$ must fall, which means the total number of firms rises. Trade 
distortions are high enough that every firm will jump all of them. However, the number of production plants in the PTA will fall. Using market clearing conditions analogous to (16) and supply equations (5)-(7) and assuming all firms are of the same type, it can be shown that the number of firms, $z$, is given as

$$
z=\sqrt{\frac{H}{1+2 y}},
$$

where $H$ is the ratio of total fixed cost to $X$ expenditure for the given firm type. It is then the case that

$$
1<\frac{m_{u}}{m_{A B}}=\sqrt{\frac{3 g+f}{2 g+f}}<1 \frac{1}{2}
$$

for all finite, positive values of $g$. Since the number of plants in the PTA per firm is halved but the number of firms less than doubles, the number of plants in the PTA will fall and that region will see less aggregate investment.

For trade costs between $t_{3}$ and $t_{4}$ there is some indeterminacy. For trade costs closer to $t_{3}$ the number of firms will decrease implying an increase in production plants in the PTA following integration, while for trade costs closer to $t_{4}$ the contrary is true. Thus, there exists some value of $t$ such that the number of plants in the PTA will remain constant, though it is not clear whether or not the number of firms will remain constant at this $t$.

\section{Welfare}

With zero profits, we need only consider the welfare of consumers. Constant incomes imply that the consumers budget line is fixed in terms of the numeraire good, so welfare is simply an inverse function of the relative price of $X$. The integrating countries are made unambiguously better off as long as any multinationals exist after integration, since $p_{u}$ must in the process fall. It is interesting to note that $A$ and $B$ are better off no matter what happens to the amount of investment therein, provided there is at least some investment after integration. ${ }^{16}$ Welfare in $R O W$ is directly related to the total number of firms, and so will at first fall and then rise upon integration as initial trade costs increase. The model suggests that integration will make participating countries better off,

\footnotetext{
${ }^{16} \mathrm{It}$ is also interesting that pre-integration welfare in A and B is not strictly decreasing in trade costs. It falls until $\mathrm{t}>\mathrm{t}_{3}$, and then rises as local production increases that cuts back local markups.
} 
but for some levels of trade distortion this will be at the expense of excluded countries. Summarizing the last two subsections we submit Proposition 2,

Proposition 2: For some $t_{\mathrm{z}}, t_{3}<t_{z}<t_{4}$, the total number of firms will not change upon integration. For all $t<t_{1}$ integration will have no effect on either the number of firms or welfare of any country. For all $t$ such that $t_{1}<t<t_{z}$, integration will reduce the total number of firms, increase welfare in $A$ and

$B$, and decrease welfare in $R O W$. For $t>t_{z}$, the total number of firms will fall while the welfare of all countries rises.

Of course, these welfare results are highly specific to the interpretation of trade costs we have used. Were the trade costs in question tariffs, then the integrating countries could see some loss of income if any national firms exist before integration.

\section{E. Trade Flows}

The potential for trade diversion and trade creation has been of interest since Viner's introduction of the terms, but not nearly so frequently in the context of geographically shifting production. Recall that national firms export from the rest of the world but multinationals export from PTA countries. For $t<t_{1}$ multinationals never emerge and trade patterns are unaffected. For $t_{1}<t<t_{3}$ multinationals only emerge upon integration. Integration then entails some trade diversion and trade creation as the exports from national firms are supplanted by the production of multinationals locally and in the PTA partner. Unlike other studies without shifting production, we see here a sort of intra-firm trade deflection as firms substitute local production for exports. As trade costs rise and MNEs enter the preintegration equilibrium, there is more local production and less trade diversion. Eventually, when trade costs are high enough to fully exclude national firms, integration is entirely trade creating as MNEs service one PTA market with intraPTA exports. This is essentially because the trade distortion was bad enough that there was no trade with anyone before the PTA, and hence no trade to deflect.

\section{Conclusions}

We have examined how regional integration among countries that are potential hosts to foreign direct investment might affect the pattern of that investment. Preferential trade areas that have low individual trade costs relative to their size and the economies of scale in the multinational sector could see increased investment due to a more integrated market, while groupings with high individual 
trade costs are more likely to experience a rationalization of investment as firms concentrate production in fewer plants. Nonetheless, increased competition and economies of scale lead to lower prices for the integrating countries.

This analysis employs extensive symmetry assumptions, and considers only a narrow motivation for FDI. Future studies which allow for differences in external trade costs and marginal costs (particularly between the integrating countries and the rest of the world) are likely to uncover interesting results.

This exercise has assumed throughout that investment is horizontal in nature, with but a single stage of production. However, production is a multistage process with an ever decreasing need to have different stages located in the same physical spot. Future inquiry into the impact of regional integration on inward direct investment that recognizes segmented production would likely yield additional insights.

Submitted 10 September 1999, accepted 24 May 2000

\section{References}

Aristotelous, K., and S. Fountas (1996), “An Empirical Analysis of Inward Foreign Direct Investment Flows in the EU with Emphasis on the Market Enlargement Hypothesis," Journal of Common Market Studies 34, 571-583.

Baldwin, R.E. and A.J. Venables (1995), "Regional Economic Integration," in: G.

Grossman and K. Rogoff, eds., Handbook of International Economics, VOL. 3 (NorthHolland, Amsterdam).

Bannister, G.J., C.A. Primo Braga and J. Petry (1994), “Transnational Corporations, the Neo-liberal Agenda and Regional Integration: Establishing a Policy Framework, Quarterly Review of Economics and Finance 34, 77-99.

Bhagwati, J. and A. Panagariya (1996), "Preferential Trading Areas and Multilateralism-

Strangers, Friends, or Foes?," in J. Bhagwati and A. Panagariya, eds., The Economics of Preferential Trade Agreements (The AEI Press, College Park, MD).

Blomström, M., and A. Kokko (1997), "Regional Integration and Foreign Direct Investment: A Conceptual Framework and Three Cases,” World Bank Policy Research Working Paper \#1750.

Caves, R.E. (1996), Multinational Enterprise and Economic Analysis, 2nd ed. (Cambridge University Press, Cambridge, MA).

Ethier, W.J. (1998), "Regionalism in a Multilateral World," Journal of Political Economy 106, 1214-1245.

Globerman, S., and D.M. Shapiro (1999), "The Impact of Government Policies on Foreign Direct Investment: the Canadian Experience," Journal of International Business Studies 30, 513-532. 
Helpman, E. (1985), "Multinational Corporations and Trade Structure," Review of Economic Studies 52, 443-58.

Horstmann, I.J., and J.R. Markusen (1987), "Strategic Investments and the Development of Multinationals," International Economic Review 28, 109-121.

Horstmann, I.J., and J.R. Markusen (1992), "Endogenous Market Structures in International Trade, Journal of International Economics 32, 109-129.

Konan, D.E., and J.S. Heinrich (2000), "Regional Integration and Foreign Direct Investment," mimeo.

Lipsey, R.G. (1960), “The Theory of Customs Unions: A General Survey," The Economic Journal 70, 496-513.

Markusen, J.R. (1984), "Multinationals, Multi-plant Economies, and the Gains from Trade," Journal of International Economics 16, 205-226.

Markusen, J.R.(1995), "The Boundaries of the Multinational Enterprise and the Theory of International Trade,” Journal of Economic Perspectives 9, 169-189.

Markusen, J.R., and A.J. Venables (1998), "Multinational Firms and the New Trade Theory," Journal of International Economics 46, 183-203.

Motta, M., and G. Norman (1996), "Does Economic Integration Cause Foreign Direct Investment?," International Economic Review 37, 757-783.

Robson, P., and I. Wooton (1993), “The Transnational Enterprise and Regional Economic Integration,” Journal of Common Market Studies 31, 71-90.

United Nations Center on Transnational Corporations (1993), From the Common Market to EC92: Regional Economic Integration in the European Community and the Transnational Corporation (United Nations, New York, NY).

Viner, J. (1950), The Customs Union Issue (Carnegie Endowment for International Peace, New York, NY)

\section{Appendix}

Here we will introduce the relevant equations for single subsidiary pre-integration MNEs (type- $m i$ firms), and discuss price equilibria and the motivation for assuming no type- $m i$ firms. The pricing equation for $X$ sales in $R O W$ by type- $m i$ firms is as given in (3), and for $X$ sales in $A$ and $B$ pricing is given by (4). Outputs in terms of prices are then given by (5), (7), and (6) for sales in $R O W$, the PTA country in which the firms subsidiary is located, and the other PTA country, respectively. The equation for the zero profit locus for type-mi firm's, denoted $\pi_{m i}$, is then

$$
\frac{\left(\left(p_{R}-c\right) / p_{R}\right)^{2}}{2 g+f}+\frac{\left(\left(p_{u}-c\right) / p_{u}\right)^{2}+\left(p_{u}-c(1+t) / p_{u}\right)^{2}}{(2 g+f) / 2 y}=1
$$

with center at $\left(c \sqrt{1+t+t^{2} / 2}\right)$. The price ratio consistent with only type-mi firms 
existing is

$$
p_{R} / p_{u}=\left(1+t+t^{2} / 2\right)^{-1 / 2}
$$

which lies between $N$ and $M_{u}$.

If firms are of a single type, then the relevant price ratio can be used to substitute out one of the prices in the relevant zero-profit condition and then solve for the other price. Denoting $p_{i, k}$ as the price in region $i$ if all firms are type- $k$, we obtain

$$
\begin{gathered}
p_{u, m u}=p_{R, m u}=c\left(1-\sqrt{\frac{2 g+f}{1+2 y}}\right)^{-1} \\
p_{u, m A B}=p_{R, m A B}=c\left(1-\sqrt{\frac{3 g+f}{1+2 y}}\right)^{-1} \\
p_{u, n}=p_{R, n} /(1+t)=c(1+t)\left(1-\sqrt{\frac{g+f}{1+2 y}}\right)^{-1}, \text { and } \\
p_{u, m i}=p_{R, m i} \sqrt{a}= \\
\frac{c\left[\sqrt{a}+(2+t) y+\sqrt{\left.(\sqrt{a}+(2+t) y)^{2}-(1+2 y)(1+2 y-2 g-f)\right]}\right.}{1+2 y-2 g-f}
\end{gathered}
$$

where $a=1+t+t^{2} / 2$. Under a homogeneous regime $p_{R}$ is invariant to the level of trade costs except for $m i$ firms. It can be shown comparing the quadratic forms of $p_{R, m u}$ and $p_{R, m i}$ that the latter is less than the former by an amount that is increasing in $t$ at a decreasing rate. Since the former is constant, $p_{R, m i}$ must be decreasing in $t$.

Under a mixed regime only prices in the integrating region are tractably derived. Assuming the mixed regime contains only two firm types, we can take the relevant zero profit conditions (both of which hold) and compute their difference to determine $p_{u}$. Letting $p_{u, k l, k 2}$ denote $p_{u}$ when the two firm types are $k 1$ and $k 2$,

$$
\begin{aligned}
& p_{u, n, m u}=\frac{2 c t y}{g}\left[1-\sqrt{\frac{g(2+t)}{2 t y}}\right] \\
& p_{u, n, m i}=p_{u, n, m A B}=\frac{c t y}{g}\left[1-\sqrt{1-\frac{g(2+t)}{t y}}\right] .
\end{aligned}
$$

(A8) exceeds (A7) provided either exists as a real number $(g \leq t y /(2+t))$, consistent with prices falling in the PTA upon integration. 
Note that the mixed-regime pre-integration PTA price is independent of how many subsidiaries a multinational maintains in the PTA. Since we have found the intersection of $\pi_{m i}$ and $\pi_{m A B}$ with $\pi_{n}$, equivalent PTA prices implies equivalent $R O W$ prices. Essentially, when a firm invests it is trading off the relief from transport costs for the fixed cost of an additional plant. Since profits are held to zero, markup revenues are additive across countries, and $A$ and $B$ are identical, firms are indifferent between maintaining one or two plants in the union and prices are identical regardless. The only exception is when trade costs are prohibitive and investment is the only way to access $A$ or $B$. Then firms would choose zero or two subsidiaries, but not one; if under such circumstances it is worth it to invest in $A$ or $B$, then it is certainly worth it to invest in the other.

This result can lead to some ambiguity, as noted in the main text, where we assume that pre-integration MNEs will set up a subsidiary in both $A$ and $B$, or neither. As the set of price equilibria under single-subsidiary MNEs is a subset of the set of price equilibria under dual-subsidiary MNEs, in the main analysis we focus on the latter since it gives a broader pattern of PTA-induced price changes. However, some results may vary if MNEs are restricted to a single foreign plant and these qualifications should be mentioned. Given symmetric trade costs, an MNE could serve an export market from either $R O W$ or the PTA partner, but our assumption of two pre-integration plants necessarily prohibits the existence of exporting MNEs. This assumption will skew results related to trade creation and diversion, issues of interest in the PTA literature.

Additionally, suppose we were to assume that pre-integration MNEs limit themselves to a single plant in the integrating region rather than the two assumed in the main text. As noted above, this requires that pre-integration $p_{R, m i}$ must be less than post-integration $p_{R, m u}$. It is then the case that PTA formation must always increase $p_{R}$ if any MNEs exist after PTA formation, and ROW can never be made better off by the PTA. However, for high enough values of $t$ such that MNEs dominate production both before and after the PTA, there can still be a rationalization effect since the number of firms must fall, and each maintains a single plant in the PTA. The result that the price of $X$ in the PTA falls with integration is robust to assumptions on the pre-integration number of plants maintained abroad by MNEs. 